\title{
Late false-lumen expansion predicted by preoperative blood flow simulation in a patient with chronic type $B$ aortic dissection
}

\author{
Chikara Ueki, MD, and Hiroshi Tsuneyoshi, MD, PhD
}

\author{
From the Department of Cardiovascular Surgery, Shizuoka General Hospital, Shizuoka, Japan. \\ No sources of funding were used for this work. \\ Disclosures: Authors have nothing to disclose with regard to commercial support. \\ Received for publication Aug 2, 2018; revisions received Sept 7, 2018; accepted for publication Sept 12, 2018; \\ available ahead of print Nov 13, 2018. \\ Address for reprints: Chikara Ueki, MD, Department of Cardiovascular Surgery, Shizuoka General Hospital, \\ 4-27-1 Kita-Ando Aoi-ku, Shizuoka 420-8527, Japan (E-mail: uekichikara@gmail.com). \\ J Thorac Cardiovasc Surg 2019;157:e311-17 \\ $0022-5223 / \$ 36.00$ \\ Copyright (c) 2018 by The American Association for Thoracic Surgery \\ https://doi.org/10.1016/j.jtcvs.2018.09.108
}

$\checkmark$ Video clip is available online.

A 31-year-old man with a chronic Stanford type B aortic dissection with a false-lumen aneurysm was referred to our department. Computed tomographic angiography showed the dilated false lumen in the thoracoabdominal aorta, a primary entry distal to the left subclavian artery, and multiple reentry sites at the levels of the celiac trunk, left renal artery, lumbar arteries, and left iliac artery (Figure 1). We performed primary entry closure by thoracic endovascular aortic repair (Figure E1).

To predict changes in hemodynamics in the false lumen after primary entry closure by thoracic endovascular aortic repair, we performed a blood flow simulation with computational fluid dynamics (CFD) (Video 1). ${ }^{1,2}$ CFD analysis derived from preoperative imaging data revealed high wall shear stress (WSS) and a relatively low oscillatory shear index at the most dilated site of the false lumen (Figure 2). Furthermore, in the model in which the primary entry was closed virtually, CFD simulation showed an increase in blood flow through a reentry site at the level of the celiac trunk, with extremely high WSS and a relatively low oscillatory shear index in the false lumen at the level of the celiac trunk (Figure 3). Consistent with this prediction, imaging at 18 months after thoracic endovascular aortic repair showed that the diameter of the thoracic aorta was greatly reduced, but the aortic diameter at the level of the celiac trunk had increased from 41 to $46 \mathrm{~mm}$ (Figure 4).

Previous CFD study of nondissected aorta reported very low WSS inside the aneurysm, and high WSS

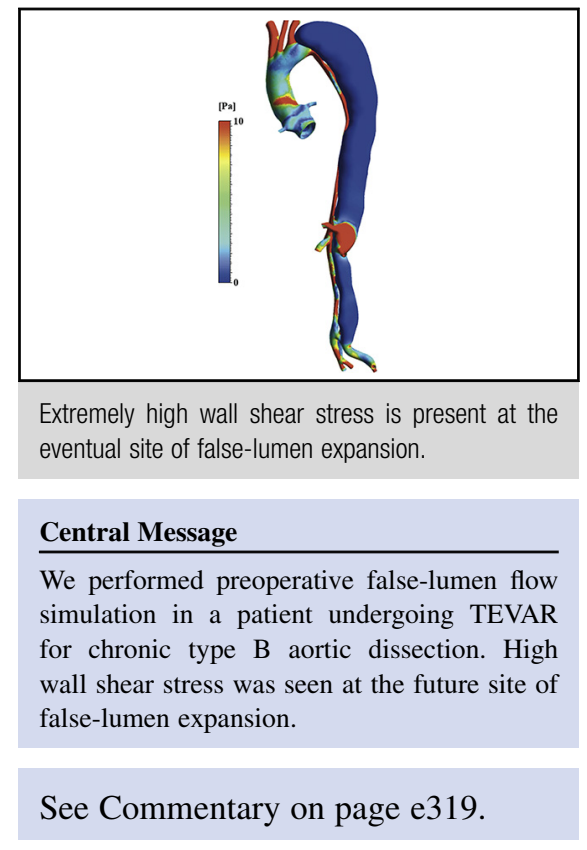

and oscillatory shear index in the lesser curvature of the descending aorta. ${ }^{3}$ In patients with type B aortic dissection, WSS is generally higher in the true lumen than in the false lumen, ${ }^{4}$ and aortic WSS is significantly higher in patients with a rapidly expanding false lumen. ${ }^{5}$ Our CFD simulation of a complicated chronic type B aortic dissection revealed that WSS is greatly increased both at the current site of false-lumen expansion and at the eventual site of false-lumen expansion. In contrast, CFD simulation of blood flow in a patient without late false-lumen expansion after thoracic endovascular aortic repair showed no marked WSS elevation in the false lumen in the model with the primary entry closed virtually (Figures E2-E4). Accumulation of data on the relationship between CFD simulation results and the clinical course is necessary to understand the relationship between WSS and false-lumen enlargement.

We thank Cardio Flow Design Inc (Tokyo, Japan; http://cfd. life/) for analyzing the data. 


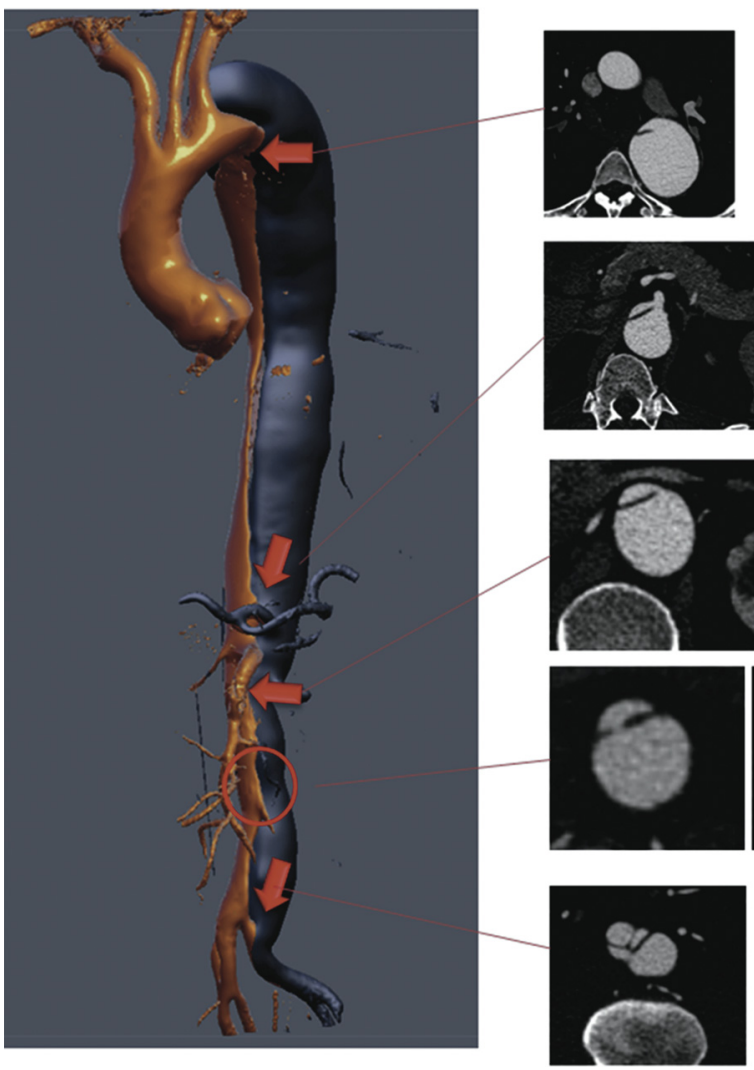

\section{Primary entry}

Celiac trunk

Lt. renal artery

Lumbar arteries

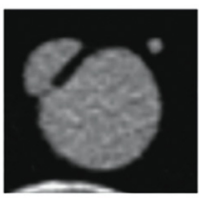

Lt. iliac artery

FIGURE 1. Three-dimensional computed tomographic angiography and axial images at the sites of primary entry and multiple reentry sites. Lt., Left.
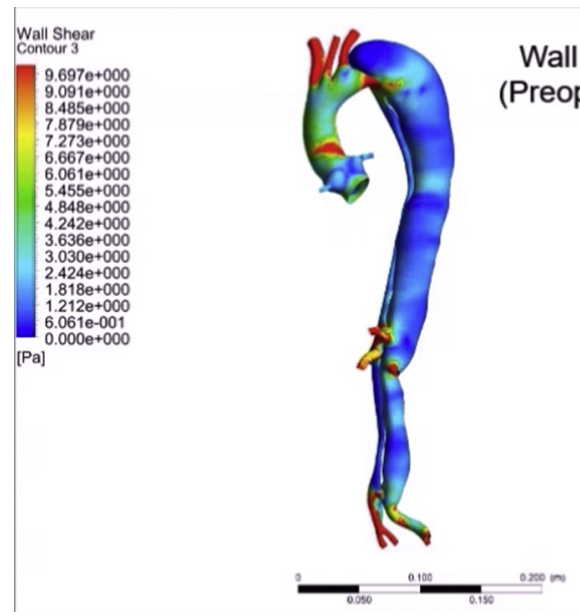

Wall Shear Stress

Preoperative Model)

VIDEO 1. Four-dimensional simulation of stream line and wall shear stress in the preoperative model and the virtual postoperative model in the described case. Video available at: https://www.jtcvs.org/article/S0022-5223(18)32652-7/fulltext. 


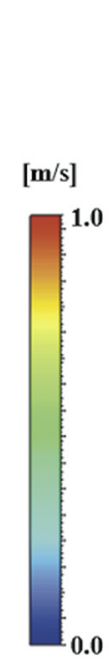

A

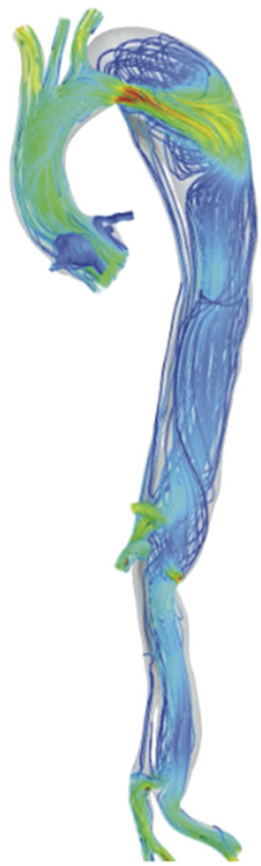

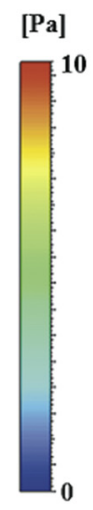

B
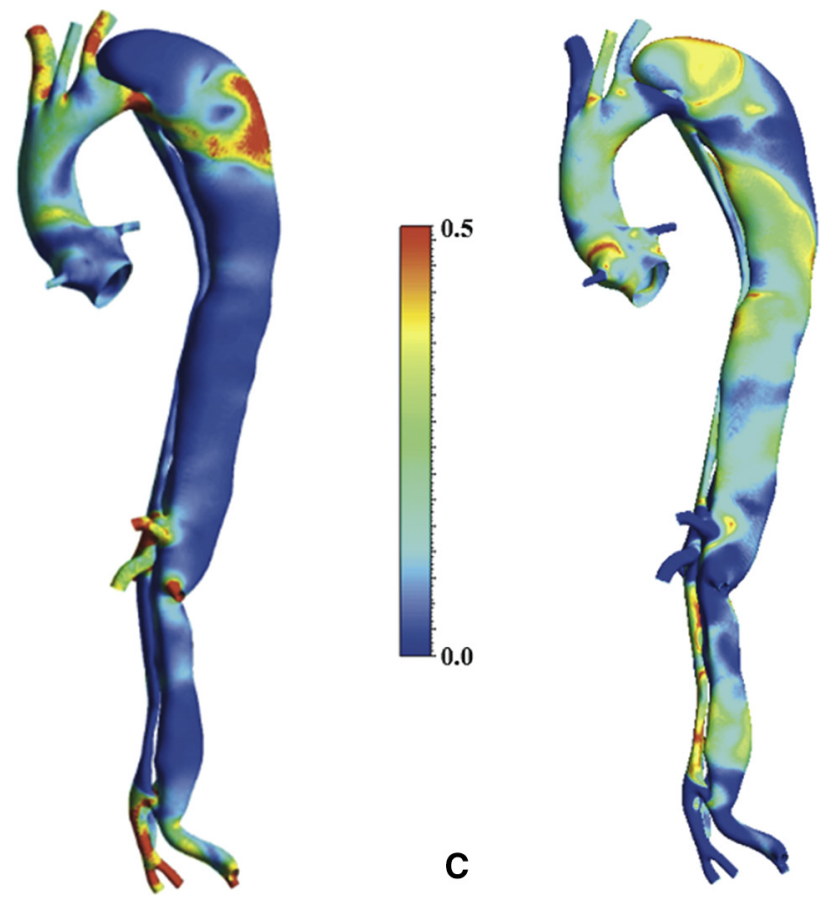

FIGURE 2. Computational fluid dynamics simulation derived from preoperative computed tomographic imaging data showed high wall shear stress at the most dilated site of the false lumen. A, Stream line. B, Wall shear stress. C, Oscillatory shear index.

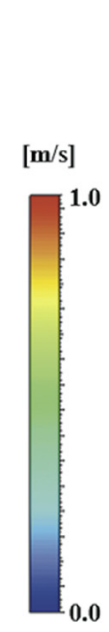

A

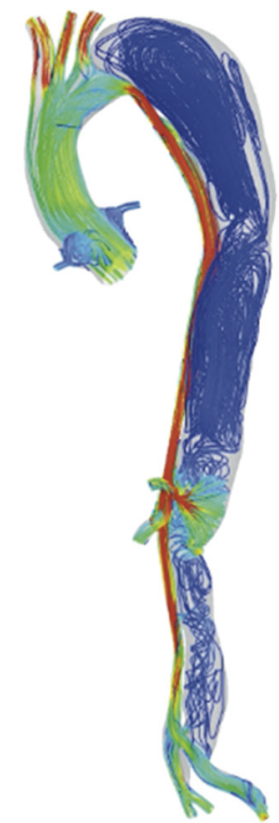

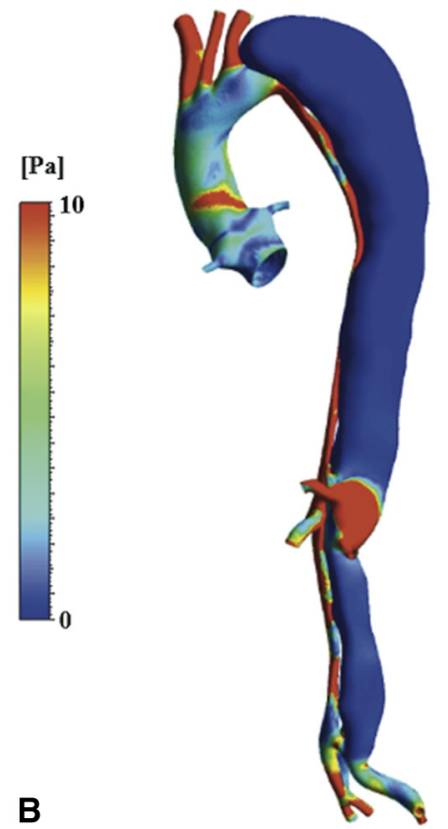

B

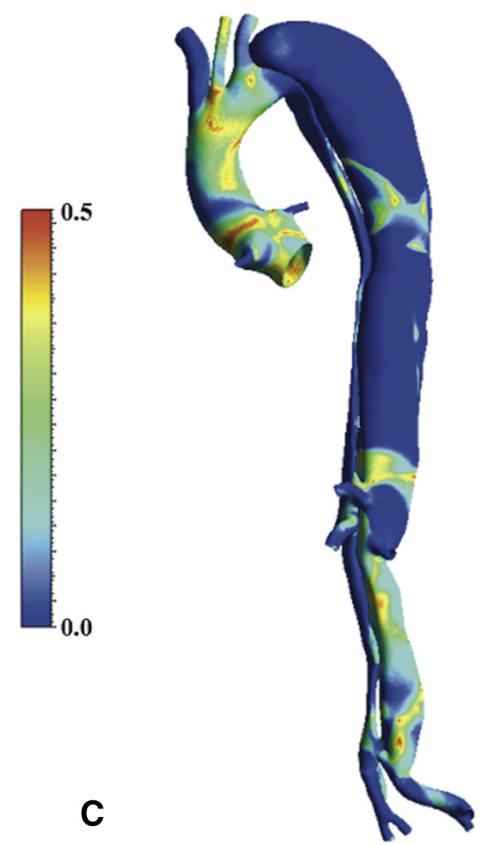

C

FIGURE 3. Computational fluid dynamics simulation of the model in which a primary entry was closed virtually showed high wall shear stress at the level of the celiac trunk. A, Stream line. B, Wall shear stress. C, Use of computational fluid dynamics studies in predicting aneurysmal degeneration of acute type B aortic dissections Oscillatory shear index. 
1)

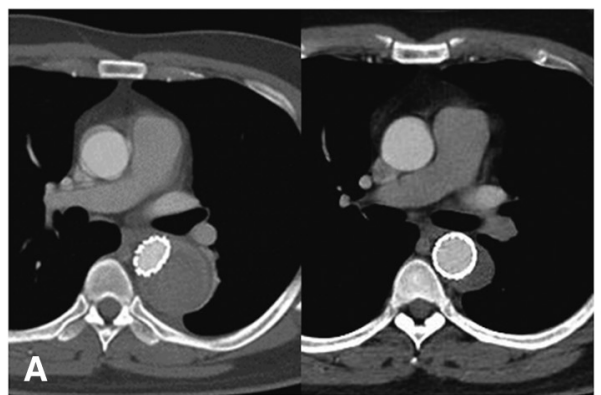

1)

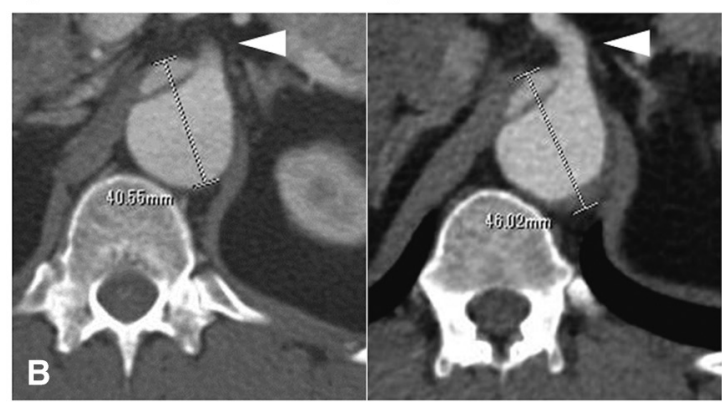

FIGURE 4. Comparison of early postoperative (A1 and B1) and follow-up (A2 and B2) computed tomographic images demonstrates shrinkage of the false lumen at the level of the pulmonary artery bifurcation and enlargement of the false lumen at the level of the celiac trunk (arrowhead).

\section{References}

1. Qian Y, Liu JL, Itatani K, Miyaji K, Umezu M. Computational hemodynamic analysis in congenital heart disease: simulation of the Norwood procedure. Ann Biomed Eng. 2010;37:2302-13.

2. Numata S, Itatani K, Kawajiri H, Yamazaki S, Kanda K, Yaku H. Computational fluid dynamics simulation of the right subclavian artery cannulation. $J$ Thorac Cardiovasc Surg. 2017;154:480-7.

3. Numata S, Itatani K, Kanda K, Doi K, Yamazaki S, Morimoto K, et al. Blood flow analysis of the aortic arch using computational fluid dynamics. Eur J Cardiothorac Surg. 2016;49:1578-85.
4. Tse KM, Chiu P, Lee HP, Ho P. Investigation of hemodynamics in the development of dissecting aneurysm within patient-specific dissecting aneurismal aortas using computational fluid dynamics (CFD) simulations. J Biomech. 2011;44:827-36.

5. Shang EK, Nathan DP, Fairman RM, Bavaria JE, Gorman RC, Gorman JH III, et al. Use of computational fluid dynamics studies in predicting aneurysmal degeneration of acute type B aortic dissections. J Vasc Surg. 2015;62:279-84. 


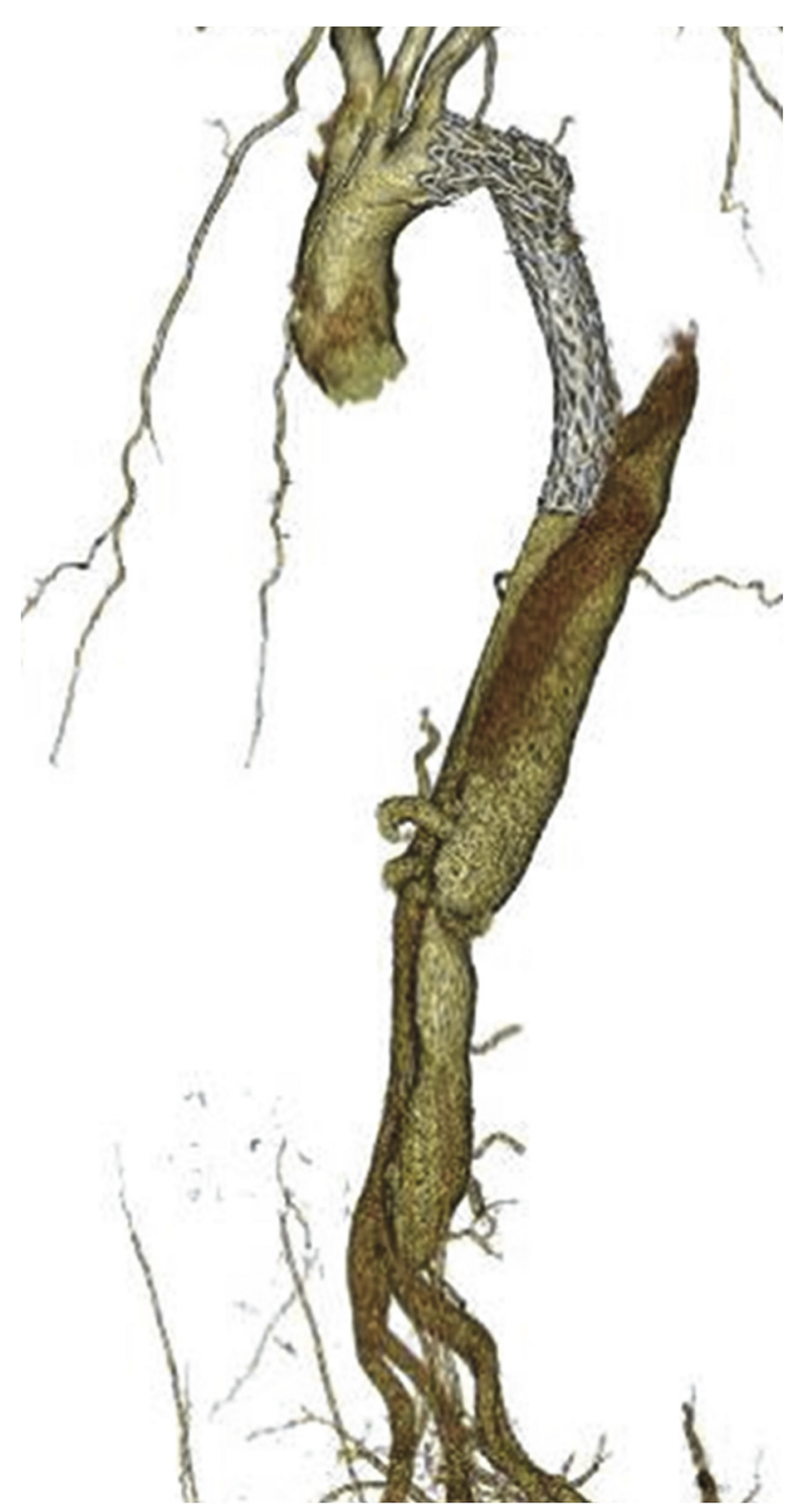

FIGURE E1. Three-dimensional computed tomographic angiography after primary entry closure with thoracic endovascular aortic repair. 


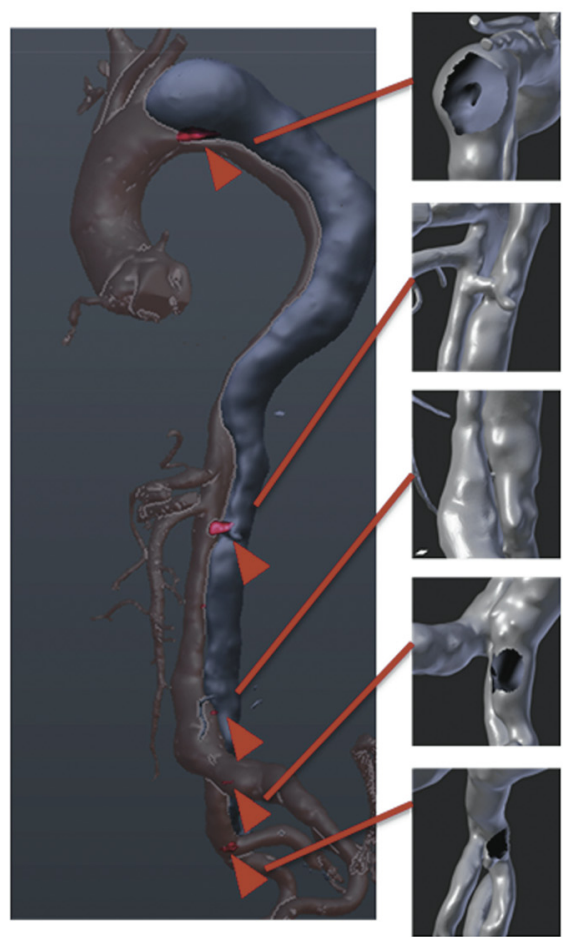

A

\section{Primary entry}

Lt. renal artery

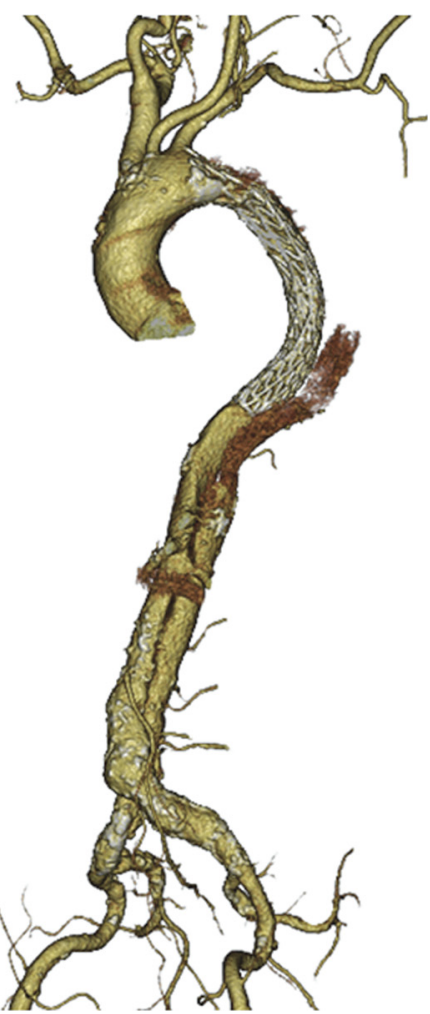

FIGURE E2. Preoperative 3-dimensional patient-specific geometry (A) and 3-dimensional computed tomographic angiography (B) after primary entry closure in a patient without late false-lumen expansion after thoracic endovascular aortic repair. $L t$., Left; $R$., right.
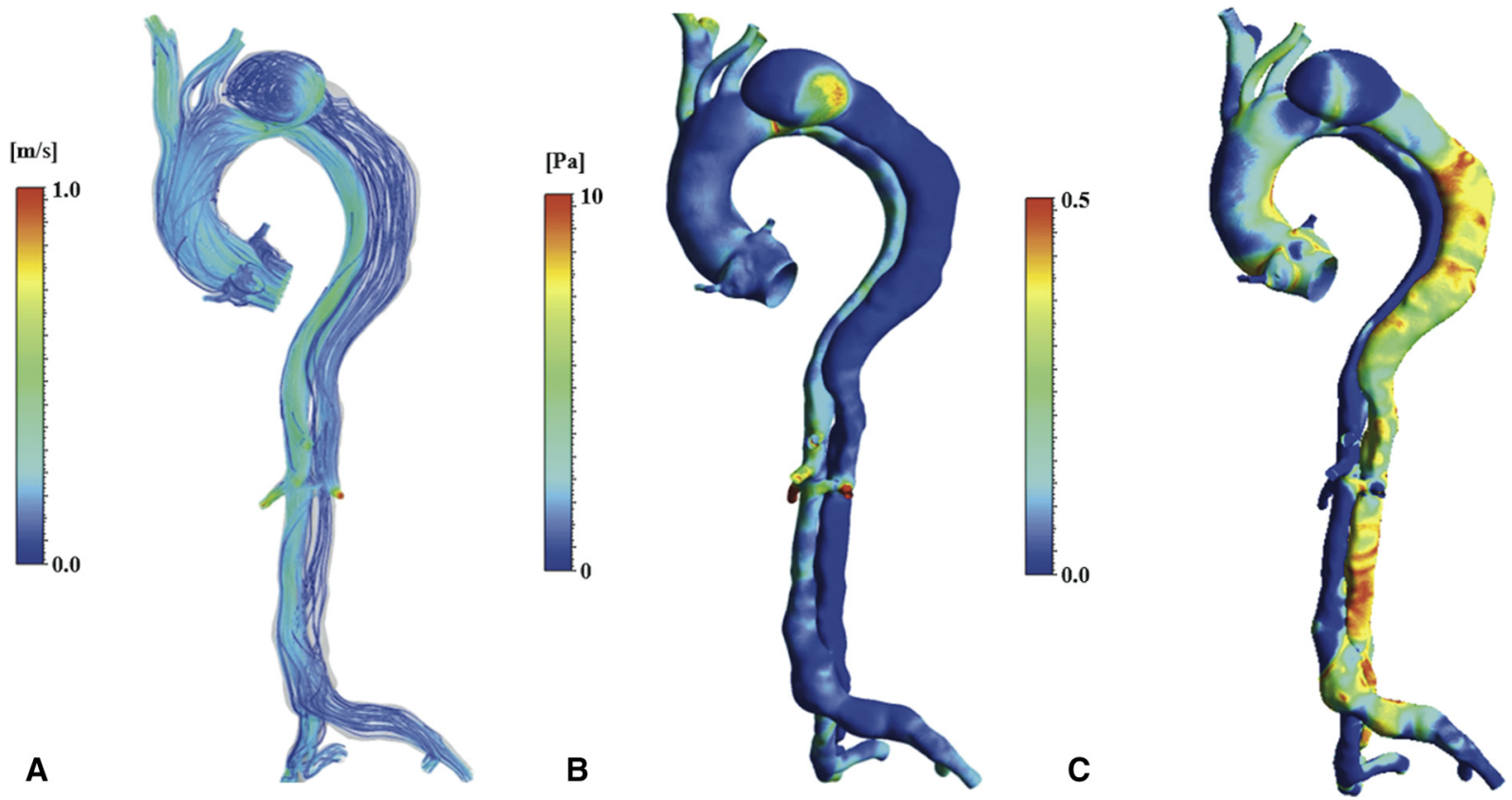

FIGURE E3. Preoperative computational fluid dynamics simulation in a patient without late false-lumen expansion after thoracic endovascular aortic repair showed high wall shear stress at the most dilated site of the false lumen. A, Stream line. B, Wall shear stress. C, Oscillatory shear index. 
Ueki and Tsuneyoshi

Adult: Aorta: Cardiothoracic Imaging
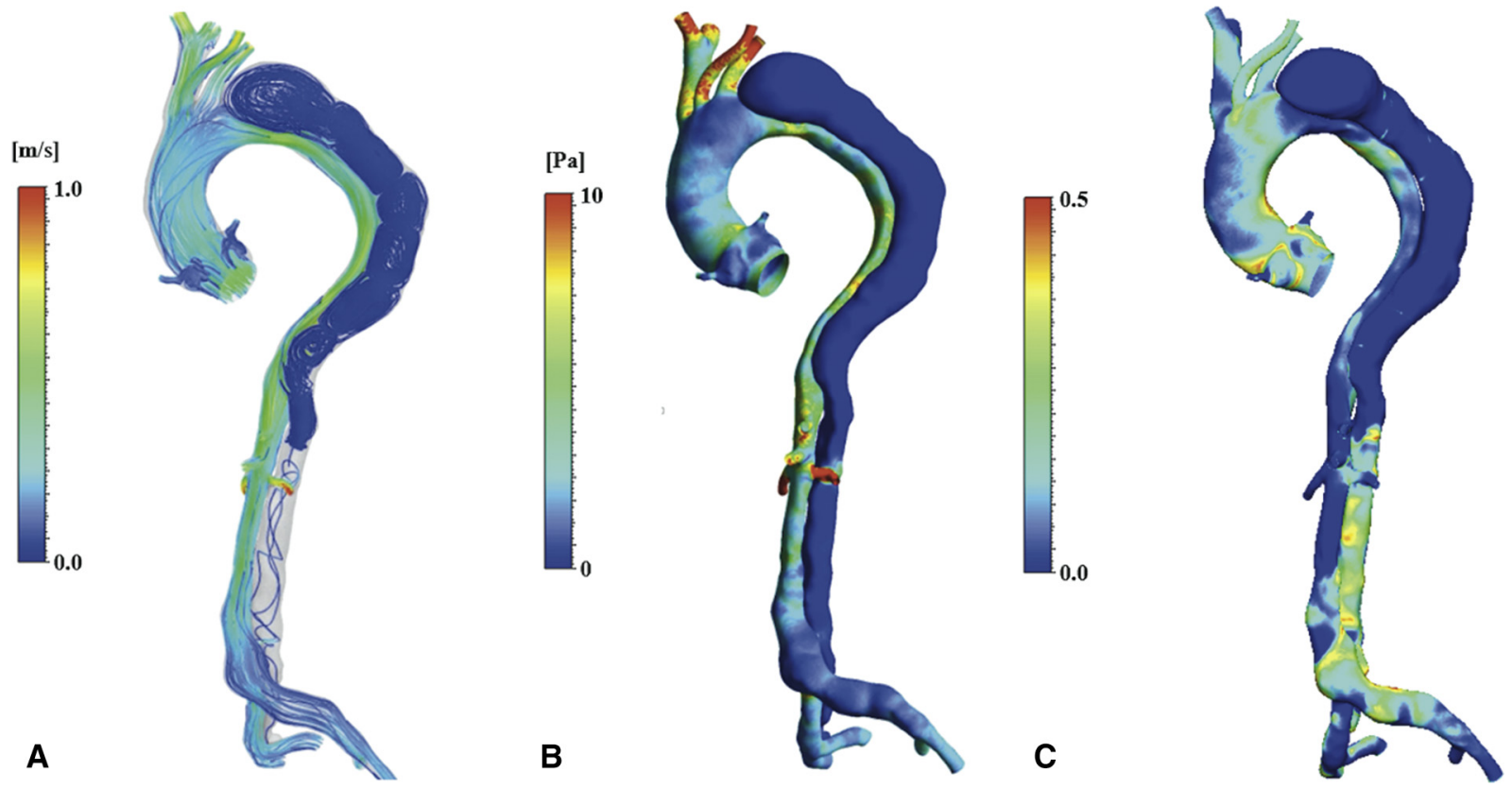

FIGURE E4. Computational fluid dynamics simulation of the model in which the primary entry was closed virtually in a patient without late false-lumen expansion after thoracic endovascular aortic repair showed no marked wall shear stress elevation. A, Stream line. B, Wall shear stress. C, Oscillatory shear index.

The Journal of Thoracic and Cardiovascular Surgery • Volume 157, Number 6

e317 